\title{
Derecho y Literatura en Latinoamérica: la aparición imbunche
}

Law and Literature in Latin America: the imbunche appearance

Camilo ARANCIBIA H.1

Universidad de Valparaíso, Chile

camilo.arancibia@uv.cl

\section{Resumen}

El movimiento Derecho y Literatura empieza a desarrollarse en Latinoamérica y ya muchos países de esta cuentan con cátedras, entidades, congresos y publicaciones que dan cuenta de ello. Este trabajo pretende explorar una vía de acercamiento a la disciplina desde el mito del imbunche como figura para pensar en nuestro continente, una poética, una literatura y un sujeto que permita comprender ese Otro, que dada la forma imperante de interpretar el Derecho (positivismo), no aparece. Para ello me basaré, principalmente, en el tratamiento del mito del imbunche en la novela $E l$ obsceno pájaro de la noche (1970) de José Donoso, en el concepto de espacio de aparición de Hannah Arendt, de polifonía de Mijaíl Bajtín y de sujeto migrante de Antonio Cornejo Polar. Con ello espero demostrar que esta otra disciplina puede servir a los efectos del Derecho para iluminar subjetividades y fenómenos asociados a ellas, que permanecen en la oscuridad.

Palabras clave: Derecho y Literatura; Imbunche; Espacio de aparición; Literatura polifónica; Sujeto migrante.

\footnotetext{
1 Abogado. Magíster en Derecho, U. de Chile. Máster en Literatura Comparada: Estudios literarios y culturales, U. Autónoma de Barcelona. Doctorando en Filosofía, U. Autónoma de Barcelona. Académico de Derecho y Literatura en la Escuela de Derecho de la Universidad de Valparaíso. Fundador del Seminario de Arte y Derecho UV.
} 


\begin{abstract}
The Law and Literature movement is beginning to develop in Latin America and many countries already have chairs, entities, congresses and publications that give an account of it. This paper intends to explore a way of approaching the discipline from the myth of the imbunche as a figure to think in our continent, a poetics, a literature and a subject that allows understanding that Other, which given the prevailing way of interpreting Law (positivism), does not appear. To this end, I will base myself mainly on the treatment of the myth of the imbunche in the novel El obsceno pájaro de la noche (1970) by José Donoso, on Hannah Arendt's concept of the space of appearance, on Mijaíl Bajtín's concept of polyphony and on Antonio Cornejo Polar's concept of the migrant subject. In doing so, I hope to demonstrate that this other discipline can serve for the purposes of law to illuminate subjectivities and phenomena associated with them, which remain in obscurity.
\end{abstract}

Keywords: Law and Literature; Imbunche; Space of appearance; Polyphonic literature; Migrant subject.

“... en esta Casa hay agujeros que no conoces

por donde entran y salen personas que tú no registras..."

(Donoso, 2021: 128)

\title{
1. El marco del Derecho: lo que no aparece
}

En las famosas conversaciones entre Pierre Cabanne y Marcel Duchamp, el primero le señala al segundo que este ha hecho estallar los límites de la creación con su obra. Duchamp señala que la palabra creación le asusta y que él no ve diferencia entre el artista y cualquier otra persona pues todos hacen cosas. Si hubiera una diferencia, apunta, es que si esas cosas se hacen sobre "un lienzo y le ponen un marco los llaman artistas" (Cabanne, 2013: 11), pero no hay más distinción que esa. Las implicancias de lo señalado son varias y variadas, pero me interesa resaltar la idea de marco asociada a la pintura.

Como sabemos, en un principio las pinturas se apreciaban en el contexto arquitectónico donde residían, pero el deseo de darle un lugar autónomo de acuerdo a su relevancia, produjo la necesidad de encuadre. Con ello la obra se aisló, se recortó de la realidad, ganando en poder de apreciación y detalle, pero a su vez, al realizarse esta escisión, la obra dejó de formar parte del continuo vital. Esa operación lleva a decir a Baudelaire, en su soneto El marco, que ese aislamiento le produce "extrañeza" y "encanto" (Ballart, 2005: 26). En efecto, la separación permite detener la vorágine 
de la naturaleza y la realidad para apreciar una parte de ellas, pero a la vez nos señala una impresión de límite, de frontera, más allá del cual no sabemos. Desde este punto de vista habrá seres y cosas que se resaltan e iluminan, pero habrá otras que no. Habrá apareceres y oscuridades.

Las ideas de telas, marcos, recortes, realidad y apareceres pueden suscitar reflexiones interesantes cuando las aplicamos al ámbito del Derecho. En efecto, la idea de frontera, de separación, de marco en definitiva, puede ayudarnos a comprender por qué son necesarios los estudios de Derecho y Literatura en Latinoamérica.

Diego Falconí ha señalado que el concepto de sistema jurídico puede ser el gran marco bajo el cual se mueve el Derecho. Él lo ha entendido como "protección y límite de un fresco gigante (o una epopeya colosal)... la vida humana" (Falconí, 2012: 22). El Derecho, ese fenómeno omnipresente, esa palabra fundante de nuestra realidad, propone recortes, esquemas, tipos, que regulan las acciones de los sujetos. El Derecho, como lo señalaba Duchamp para el resto de oficios, "hace cosas", también, dentro de un marco. Todo lo que está dentro es Derecho y lo que está afuera no lo es. La cuestión del límite asoma y es allí donde los esfuerzos positivistas posaron sus energías con el fin de desterrar todo lo no jurídico. El límite lo constituyó lo racional y todo lo que no tuviera esa característica quedó relegado a un lugar marginal en relación al Derecho. Dos ejemplos relevantes de ello son la política y la moral. Como señala Jorge Roggero: "La moral y la política caen en el campo de lo irracional, pues no son abordables mediante la metodología científica...Todo lo que no se ajusta a esta racionalidad es irracional, subjetivo, sin otra justificación posible que la apelación a las emociones" (Roggero, 2012: 175). El ideal kelseniano de pureza del Derecho, de expulsar todo lo no conforme con sus postulados, es un problema concerniente a cómo el Derecho se acompasa con la realidad, esto es, cómo puede vincularse con ella sin encerrarse en sí mismo. Si la faz predominante en el Derecho es la normativa, entonces todo lo que aparece en él se mira bajo ese cariz, con lo cual el Derecho realiza un recorte sesgado de la realidad no permitiendo que afloren en él otros elementos. Con ello se obtiene un Derecho ensimismado y articulador de un lenguaje privado que lo desconecta del mundo.

Así concebido, el problema de suprimir herramientas para comprender la realidad es que, sin ellas, lo Otro (esas subjetividades y fenómenos asociados a ellas) que no aparece en el Derecho, no tiene posibilidad de existencia. A propósito de eso Otro, Hannah Arendt señalaba que, en el mundo, ser y apariencia coincidían pues, "nada puede aparecer; el término 'apariencia' carecería de sentido si no existiesen receptores de las apariencias, criaturas vivas capaces de percibir, reconocer y reaccionar... frente a lo que no sólo está ahí, sino que aparece ante ellos y tiene significado para su percepción" (Arendt, 2020: 43). Si, entonces, nos constituimos por la percepción del otro, al restarnos de esa empresa oscurecemos una parte del mundo y, a su vez, nos oscurecemos. La cuestión, de contornos ontológicos, se revela política 
también pues, ¿qué agencia puede tener el que no se revela como existente? En la esfera pública, ninguna. Pero, más allá, ¿qué agencia puede ostentar el que aparece, pero es tratado como infractor (el inmigrante), como subordinada (la mujer), como perverso (las personas LGTBIQ+) o como inferior (los miembros de los pueblos originarios)? De nuevo, ninguna.

Si pensamos en nuestros países de Latinoamérica y su cultura legalista, o sea la que reduce el Derecho a lo dispuesto por la ley, el ejercicio cae en la noche cerrada. Ligar esta cuestión a la realidad latinoamericana no es un ejercicio baladí pues el aterrizaje de los estudios de Derecho y Literatura en nuestras tierras puede presentar nuevas sendas y formas de concebirse atendido el suelo donde se posa. Desde ese punto de vista no parece desacertado pensar el puente entre una y otra disciplina a propósito de los mitos latinoamericanos. Pienso en ello por tres razones: la primera es que el mito, como tal, puede ayudarnos a comprender aspectos de la realidad que estamos desatendiendo pues, atado a la historia, huye de ella para volver nuevamente, generándose en este movimiento preguntas y respuestas, esto es, un tipo de conocimiento, que en los esquemas formales de las ciencias no podemos hallar (Valdivieso, 1990: 276); la segunda es que el mito ha sido casi una obsesión para ese buque insignia llamado "novela latinoamericana", que ha buscado en ellos el núcleo de este continente, sus contradicciones y su futuro; y en tercer lugar, pues al ir al origen de la literatura latinoamericana nos encontramos, como si se tratara del monolito negro de 2001: odisea al espacio, con la ley, ese monumento alrededor del cual se ha señalado deriva la novela como tal. Esto queda bien explicado por González: "En Mito y archivo propongo una teoría acerca del origen y evolución de la narrativa latinoamericana y el nacimiento de la novela moderna. Postulo que la novela se derivó del discurso legal del imperio español durante el siglo XVI" (González, 2000: 9). De esa manera mito, literatura latinoamericana y ley se unen produciéndose entre unos y otros diálogos que pueden hacer que en el Derecho aparezca lo que hoy no está teniendo lugar.

En las siguientes páginas describiré un mito fundamental dentro de la tradición mapuche, como lo es el imbunche y obtendré, a partir de él, una poética, una literatura y un sujeto, a tener en cuenta para el movimiento en estudio.

\section{Por un Derecho y Literatura imbunche}

En 1998, Enrique Marí señaló que a la academia en Derecho le iba a ser difícil aprovechar los frutos de esta disciplina pues se encontraba en un estado de ceguera, sordera y mudez (Marí, 1998: 287). No deja de ser curioso que un Derecho como el descrito, esto es, encerrado en sí mismo, poseedor de un lenguaje privado que no logra conectar con el mundo, se avenga, paradójicamente para nuestros efectos, con el mito mapuche del imbunche. Este, llamado también, invunche, ivunche, vuta macho, 
machucho, chivato de la cueva (Plath, 2016: 253), es caracterizado como un niño de corta edad que es robado por los brujos, al cual luego de someterlo a tormentos, se le obstruyen todos los agujeros naturales del cuerpo, partiendo su lengua en dos y quedando su cara vuelta hacia atrás y su pierna atada a la espalda. Luego se le encierra en una cueva (Sepúlveda, 2010: 18,19).

En el caso de la novela El obsceno pájaro de la noche de Donoso, el mito se comporta como "una galaxia de significantes" (Valdés, 1975: 128) o una "zona de legalización” (Droguett, 1971) estética, filosófica, histórica, política, del poder, corporal, económica o sexual que envuelve a los protagonistas de la misma (amos y sirvientes del Chile de mediados del siglo $\mathrm{XX}$ ), quienes se reconocen unos a otros como parte de un mundo tenso, pero compartido. El protagonista de la novela es el Mudito (sujeto que, como su nombre lo indica, no tiene la facultad de utilizar la palabra) quien narra lo sucedido con sus patrones (el matrimonio de aristócratas compuesto por Jerónimo de Azcoitía e Inés Santillana), el resto del personal de servicio y él mismo como secretario de Jerónimo, en dos casas centrales: la Casa de Ejercicios Espirituales de la Encarnación de la Chimba, un convento del siglo XVIII regentado por monjas, donde encontramos a las viejas que cuidaban desde pequeños a los miembros de la clase alta, las cuales, enfermas y señaladas como brujas, conviven ahora con niñas huérfanas. La segunda es la Casa de la Rinconada, que acoge al hijo monstruoso (Boy) concebido por Inés y el Mudito quienes, bajo el influjo de la Peta Ponce, bruja que corresponde al "mundo de abajo, de la siniestra, del revés, de las cosas destinadas a parecer escondidas sin jamás conocer la luz" (Donoso, 2021: 163), esquivan la esterilidad del macho Jerónimo de Azcoitía y aseguran su descendencia. Entre ambas casas, entre hombres y mujeres, entre patrones y sirvientes, entre Jerónimo y el Mudito, entre Inés y la Peta Ponce, etc., se produce un juego de espejos que deforma a los personajes, altera sus identidades y donde se producen dinámicas de poder recíproco en las que el reconocimiento, la aparición y el ocultamiento son la moneda de cambio. En palabras de Valdés: “...el poder vuelve imbunche a todos aquellos sobre quienes se ejerce" (Valdés, 1975: 143).

Ante la caracterización señalada, no es difícil entender que el mito del imbunche normalmente haya sido asociado a conceptos como lo feo, la destrucción, lo salvaje, el miedo, la represión (véase en la bibliografía el estudio de Uribe sobre el tratamiento que da Joaquín Edwards Bello al imbunche). Pero, por otro lado, este mito lo encontramos en la que es considerada la primera novela chilena (Don Guillermo del año 1860, cuyo autor es José Victorino Lastarria) y está a la base, como hemos visto, de la obra mayúscula de José Donoso². Se trata de un mito fundamental que, pienso, puede reinterpretarse para hacer de él una categoría fértil en los estudios de Derecho

2 Ya en el Arauco Domado (1596) de Pedro de Oña encontramos este mito referenciado. Contemporáneamente lo apreciamos en el trabajo visual Imbunches (1977) de Catalina Parra y lo leemos en la novela La muralla enterrada (2001) de Carlos Franz. 
y Literatura. Esta reconsideración consistiría en poner en diálogo el espacio de la cueva (las casas de la novela de Donoso), los sujetos que la integran y la palabra como vínculo entre ellos, con el objeto de formar un mundo. En ese sentido, el espacio debe entenderse como uno de donde se pueda entrar y salir, un lugar de tránsito desde una oscuridad a la luz, no negando entonces la heterogeneidad de ese sujeto, sino asumiéndola como una posibilidad de estar.

Si ello es así, entonces la palabra puede convertirse en la mediadora entre ese sujeto y el mundo al cual acceder. El arte, la literatura, puede ser una manera de leer y ser leído para así reconocer la existencia de eso Otro, desconocido, a priori irracional, que, una vez incorporado, puede ser percibido. Lo señala claramente el Mudito cuando se dirige a su hijo Boy rogándole para que no deje de leer sus escritos personales: "Vas a dejar mi libro y te vas a ir para siempre sin saber quién soy, a quién le debes todo lo que eres y lo que no eres, no te vayas, Boy, no te vayas, reconóceme siquiera un instante, págame el hecho de existir..." (Donoso, 2021: 143).

En lo que sigue, esas cuevas, esas casas, ese espacio, en definitiva, vamos a señalarlo como la poética del Derecho y Literatura (2.1), mientras que la palabra la inscribiremos en lo que consideraremos literatura polifónica (2.2) y el sujeto lo ligaremos con el concepto de sujeto migrante (2.3). Sobre el mundo nos pronunciaremos en las conclusiones.

En la tensión entre estos conceptos, en la caracterización del imbunche de Donoso como terror, pero, "a la vez un fin perseguido, ansiado; el imbunche es indefenso, anulado, y a la vez terriblemente poderoso" (Valdés, 1975: 140), se juegan, pienso, los problemas y categorías del Derecho y Literatura en nuestra tierra.

\subsection{Una poética latinoamericana: el jardín de al lado}

Decía el recordado profesor malagueño, José Calvo, que su visión de lo que él llamaba acertadamente "Teoría Literaria del Derecho" podía representarse en la figura del jardín pues se trata de un "terreno cercado donde, habiendo permanecido al abrigo del inclemente invierno, adelantan para el estudio brotes de alguna especie difícil, singular o nueva" (Calvo, 2021: 297, 298). En un pasaje de El obsceno pájaro de la noche, el Mudito dice que él guarda las llaves de todas las puertas de la Casa. Se refiere a la Casa de Ejercicios Espirituales, caracterizada como un lugar "abierto a habitaciones donde las telarañas ablandan las resonancias y a galerías donde quedaron pegados los ecos de tránsitos que no dejaron noticia” (Donoso, 2021: 29).

Tanto en el jardín como en la Casa descrita (este "jardín de al lado") hay una diversidad de seres y fenómenos dispuestos a salir del largo invierno. Para que puedan germinar es necesario una poética a la altura. Esto se puede ligar con las ideas del académico peruano Antonio Cornejo Polar sobre la teoría latinoamericana. Decía él en una entrevista de 1994: "No se trata de caer en el provincianismo que de alguna 
manera 'prohíbe' usar instrumentos teórico-metodológicos europeos o norteamericanos, sino de emplearlos sensatamente de acuerdo a nuestras necesidades y por supuesto con libertad, adecuándolos flexiblemente a lo que queremos examinar" (Galster, 1994: 104). La pregunta sería: ¿cómo abrir las puertas y ventanas por donde pase la luz que hará aparecer lo no visto? Se trata de hacer del espacio metodológico del Derecho y Literatura uno que permita el despliegue de las apariencias que, como señalábamos antes, coincide con la presencia y visibilidad de los seres. Este espacio de aparición (en la terminología arendtiana), esto es, aquel que se conforma por la palabra y por la posibilidad de su uso entre iguales, debe permitir la exhibición de diversas pluralidades y voces (Sánchez, 2003: 246). En ese espacio nos constituimos como sujetos y somos capaces de percibir la realidad y de ser percibidos por los demás, por lo que su construcción debe ser rigurosamente pensada, pero, al mismo tiempo, abierta en su extensión.

Para ello, el primer reto consiste en establecer el trato metodológico que se brindará a la literatura, donde brilla con especial tino la sentencia de Henriete Karam relativa a que el fracaso de los estudios en comento pasa por considerar a la literatura como un "objeto decorativo" (Karam, 2019: 4). En ese sentido, lo que debemos hacer es, al revés, honrar su historia y métodos a la par del Derecho, pues sin ello la primera pierde las características fructíferas para la relación. Como señala Terry Eagleton en el prefacio a Cómo leer literatura: “...no pueden plantearse aspectos políticos o teóricos acerca de textos literarios sin un cierto grado de sensibilidad para con el lenguaje utilizado." (Eagleton, 2017: 11) La disciplina Derecho y Literatura debe buscar un equilibrio conceptual entre una y otra para que la conjunción sea próspera y respetuosa de los tiempos y problemáticas de cada una. Una pauta para ello es atender a la teoría literaria latinoamericana que se ha desarrollado durante décadas, la cual puede ayudar a "situar este conocimiento interdisciplinar" (Falconí, 2016: 13). Dicho lo anterior, y con el objeto de salir de esa cerrazón positivista que indicábamos más arriba, debe existir una apertura de los textos literarios a analizar que nos provea de diferentes miradas y formas. Así, entonces, podemos empezar con el Borges del ensayo El escritor argentino y la tradición y decir que nuestra tradición es la occidental y nuestro patrimonio es el universo, pero a la par, podemos entender con Ivonne Coñuécar, que no terminamos de pertenecer a esa entidad universal y escuchamos una voz primigenia: "Era un fantasma que me llevaba por las escaleras a un lugar con altura para buscar mi tierra, debes volver a la Patagonia dice y duelen los ojos recreando la pampa donde corría, entonces yo era un niño y jugaba en lugares deshabitados" (Pereira). Una síntesis quizás la podríamos encontrar en lo escrito por Camila Sosa Villada: "Conviven los espantos y la belleza día a día en este mundo que hago con mis manos sucias" (Sosa, 2020: 38).

Ese diálogo entre un pasado y un futuro, entre lo local y lo global, del uno y lo diverso, da también una idea del tipo de literatura que se podría intentar en la 
disciplina.

\subsection{Una literatura polifónica: un texto que escucha}

Mijaíl Bajtín publica en 1929 su libro Problemas de la obra de Dostoievski que, ampliado y complementado, se convertirá en 1963 en Problemas de la poética de Dostoievski. Allí, ya en su primera página, se introduce en la discusión acerca del autor/sujeto poético que rendirá frutos tan dispares durante la historia de la teoría literaria: "Cuando uno empieza a estudiar la abundante literatura crítica acerca de Dostoievski, da la impresión de que no se trata de un solo autor que escribió novelas y cuentos, sino de un conjunto de discursos filosóficos pertenecientes a varios autores y pensadores" (Bajtín, 2017: 57). ¿Qué ocurre cuando el autor profesa varias ideas a la vez e, incluso, unas se contradicen con otras? El nombre que el teórico le dio a esa situación fue el de polifonía.

Si la monofonía corresponde al imperio de una sola voz que da sentido al texto, la polifonía es caracterizada como esa donde prima la "pluralidad de voces y conciencias independientes e inconfundibles, la auténtica polifonía de voces autónomas..." (Bajtín, 2017: 59).

Las obras literarias, nos dice Bajtín, pueden leerse bajo estos parámetros. Es así como Los hermanos Karamazov con sus múltiples personajes y puntos de vista, se muestra como una fiel representante de la novela polifónica. El autor trae al texto una pluralidad de matices, de formas, de fenómenos y de sujetos logrando enriquecer la obra misma de tal manera que la experiencia del lector es integral e inacabada.

Ello ocurre en el cuento de Patricio Pron titulado Los exploradores del abismo, donde asistimos a los rituales sexuales de un matrimonio joven. La pareja ha consentido que la mujer tenga relaciones sexuales con otros, pues esa es la única manera de mantener el vínculo entre ellos de manera estable. Los hechos de violencia que ella sufre en cada encuentro hacen cuestionar al lector la opción elegida, pero el marido señala: "Ése, el requisito de que ella me lo cuente todo, es el único que apuntala nuestra relación y es el único rastro de amor y de honestidad por aquí..." (Pron, 2011: 206). El relato es incómodo y nos hace repensar la institución del matrimonio, la libertad sexual reglamentada en él, además de las formas de relaciones personales que la ley prescribe.

Las voces de los personajes hacen que la obra se abra a nuevas posiciones, permitiendo una reflexión mayor. El texto no vocifera dogmas, escucha. Desde este punto de vista entendemos la idea de Barthes cuando se refiere a la escritura: “...escribir es dejar que otros cierren por sí mismos la propia palabra de uno" (Barthes, 1977: 329, 330).

Ello ocurre también con el lenguaje obturado del imbunche, cuyo encierro provoca delirios de ficción, donde la palabra se escurre sin límites. Se trata de escuchar 
esa lengua partida en dos para habilitar nuevas rutas y adentrarnos en caminos por los que el lector no ha transitado, mostrando eso que no ha sido visto. Por lo mismo, pienso, es importante tratar con literatura que no sea como esas favolettes que piensan moralmente por nosotros "para que nosotros solo tengamos que sentir" (Luque, 2020: 15). Se trata de arriesgarse a lecturas ambiguas, no taxativas, demostrativas de un rol crítico frente al fenómeno/sujeto, esto es, que permitan apreciar los matices y desde ellos interrogar/interrogarnos. No podemos volver a atestiguar un aparecer puro. Es significativo que ante el asombro de Jerónimo por el nacimiento de su hijo monstruoso, este opte por construirle la Casa de la Rinconada para que allí lo anormal sea lo normal. Prueba así otra dimensión de las cosas, "otros cánones, otros modos de apreciar el bien y el mal, el placer y el dolor, lo feo y lo bello" (Donoso, 2021: 146).

La pueril división entre buenos y malos en literatura sólo puede llevarnos a un régimen donde el lector busca ser agradado y el conflicto apagado. Habría que leer, entonces, contra nosotros mismos, allí donde nos encontramos en un sitio incómodo, fuera de lo conocido. De esa forma le damos autonomía al lector y al contenido de la obra, con lo que generamos un espacio de aparición de eso Otro de manera íntegra, en su complejidad contradictoria.

Esa emancipación permite una revelación de la identidad de los sujetos que, amén de ontológica, es política si por tal entendemos, junto con Arendt, ese espacio donde tiene lugar lo que realmente da sentido a la vida humana: "la política centrada en el discurso y la acción, insistiendo en la necesidad de ese espacio en el que se revela la identidad de los sujetos" (Sánchez, 2003: 246). Esa identidad vista como una falta, "una identidad sin plenitud" (Hozven, 2012: 158), es la que dota de sentido el último apartado de este trabajo.

\subsection{Un sujeto migrante: diálogo con el mundo}

La pregunta por el sujeto contemporáneo se encuentra al centro del debate y para esta investigación, el origen del mismo lo encontramos en la reglamentación hecha por la Ilustración reflejada en nuestros Códigos. Allí no encontramos a ese sujeto contrahecho, deforme, sino a su doble opuesto, el buen padre de familia, el sujeto esmerado, el jefe de la sociedad conyugal, etc. La literatura puede revelar a ese agente pues, como señala Mayer, ella "entra en la categoría de lo singular y obedece sus leyes" (Mayer, 1977: 11), como si fuera un espejo del Derecho, uno que muestra eso que no aparece en él, dentro de su marco. La literatura posibilita otros marcos de comprensión a propósito del caso particular, suspendiendo las categorías abstractas y estereotipadas con que opera el Derecho. En ese sentido, dejando de lado la pureza a que aspiraba el Derecho en Kelsen, el sujeto contemporáneo se comporta como uno complejo, disperso, múltiple que ostenta, por lo mismo, identidades disímiles, oscilantes, heteróclitas (Cornejo, 2003: 12 - 14). 
El Mudito, poseedor de las llaves de las Casas y, además, tenedor de su identidad fluida, señala ese tránsito como "la libertad de no ser nunca lo mismo porque los harapos no son fijos, todo improvisándose... uno es lo que es mientras dure el disfraz" (Donoso, 2021: 140). La categoría de sujeto migrante puede ayudarnos a comprender esta cuestión.

En la evolución del pensamiento de Cornejo Polar encontramos que, lo que partió como la noción de heterogéneo, esto es, esa producción literaria compleja donde convergen en un solo espacio textual dos sistemas socioculturales distintos (Cornejo, 1980: 88), pasa en una fase diferente de sus investigaciones a la noción del sujeto migrante, o sea, uno que se mueve dentro de un "espacio de negociación del cual pueden surgir tanto sentimientos de alienación y desarraigo como enriquecimientos múltiples, resultantes de los nuevos desafíos que abre la experiencia de reterritorialización" (Moraña, 1999: 24). Esta aproximación me parece fructífera por el puente que establece entre sujeto y mundo.

El poemario El territorio del viaje de Daniela Catrileo, puede dar una idea de lo que venimos señalando. Allí nos encontramos con una mujer de ascendencia indígena que, tras veinte años de vivir fuera del territorio mapuche, regresa a esa zona. Ella se siente convocada ("después de veinte años / supe que mi corazón / latía con otro nombre"), pero sabe también que su ausencia tiene un peso ("Aparece una mujer / le pido una cerveza. / - Usted no es de aquí, dice / ¿Cómo responder aquello") (Catrileo, 2017: 13, 19). Así, el viaje que emprende la protagonista no es lineal, sino que la confronta con su pasado y presente.

Conoce a las familias que integran la zona y se hunde en el territorio donde se producen los combates entre el Estado y los miembros del pueblo mapuche. Parece encontrarse en paz: "La vida acá sucede de tal manera que una quisiera nunca volver...", pero sabe que, pese a su nombre, hay un espacio que no la reconoce totalmente: “...Siempre es fácil hablar desde la distancia. En el juego y en el fuego es otra cosa" (Catrileo, 2017: 33). El problema que se plantea en el poemario es uno de larga data: ¿cómo se construye la identidad propia?, ¿cómo se construye la identidad del territorio que pisamos?, ¿cómo dialoga el sujeto y el espacio?

Una manera de plantear el problema es a propósito de lo que Arendt denominaba "privación de mundo", que consiste en un estar completamente desposeído de la capacidad de ver y oír a los demás, de ser visto y oído por ellos (Arendt, 2019: 67). En el caso de las ideas que venimos señalando, un imbunche reconcentrado en su cueva, hablando una lengua privada. Esta opción nos lleva a un solipsismo que Arendt combatió duramente en sus escritos. Lo hizo así pues el ser humano necesita de los otros para reconocerse, necesita esa lectura del otro. Las reflexiones de la protagonista del poemario de Catrileo se inscriben en este espacio pues sabe que el territorio le devuelve una imagen que, sujeta a problematización, será una que la acompañe en su autopercepción. De esta forma la cuestión identitaria 
pasa por el espacio al que accedemos, al que vamos perteneciendo. En esa mirada de los otros, se constituye esa "mujer hombre monstruo que mira superficies fuera de sí", al decir de Catrileo (2017: 47).

En el sujeto migrante (viajero desde el pasado al futuro, del adentro hacia afuera, de un lenguaje a otro, y viceversa) encuentro una posibilidad interesante de ligar estas identidades cambiantes con el espacio que tenemos en común con otros, pues, como señala Cornejo Polar: "No hay mímesis sin sujeto, pero no hay sujeto que se constituya al margen de la mímesis del mundo" (Cornejo, 2003: 15).

\section{Conclusiones}

Siempre que se confrontan dos ramas del saber (en nuestro caso, Derecho y Literatura), se producen desconfianzas mutuas, miradas reprobatorias, ejercicios de fuerza. Los detractores de estos estudios señalarán justamente el conflicto como una debilidad de la disciplina. Pienso, al revés, que allí se encuentra su potencial. Es en el tira y afloja de la palabra, esa palabra lanzada como una mano al Otro, que se puede habilitar un mundo. La pregunta es: ¿qué mundo? En la novela se nos dice: “...un mundo perdido más atrás de otros mundos perdidos más atrás de otros mundos perdidos" (Donoso, 2021: 137). Acá hay una señal.

Señala el escritor Álvaro Bisama que el mérito fundamental del libro de Donoso es que convierte "la ficción en el basurero de la Historia. Algo que contiene los escombros de sus mitos de origen y de las promesas sobre su futuro" (Donoso, 2021: 11). Esta descripción me permite señalar que una vía idónea de encarar los estudios de Derecho y Literatura en nuestro continente es la de, como si fuera un Dios Jano local, prestar atención al imbunche cuando camina hacia adelante, pero estar avisado de su cara vuelta hacia la espalda. Esto significa entrar y salir de la cueva, recoger el lenguaje particular y observarlo en público, estar atento a los claroscuros que impone el tránsito adentro/afuera. Para ello es menester delinear una poética que no caiga en el provincianismo señalado por Cornejo-Polar, sino que se transforme en un método y espacio riguroso y amplio que dé forma a un lenguaje conceptual propio de la disciplina. Se trata de un lenguaje imbunche, o sea, uno que "mantenga el respeto necesario frente al texto, de modo que no se le impongan esquemas que le sean ajenos; pero que al mismo tiempo vincule...la obra literaria con alguno de los otros esfuerzos que el hombre ha hecho por comprenderse a sí mismo y al mundo en que vive" (Valdés, 1975: 149). Para poder realizar ese movimiento será necesario contar con una literatura que permita situar (situarnos) al sujeto (situar el conocimiento) en su entorno, lo que exige una complejidad que dé cuenta de las particularidades de los diversos fenómenos, una que permita la voz de aquellos que la crónica no registra su grito "porque mi voz no se oye" (Donoso, 2021: 181). La polifonía bajtiniana amén de literaria, rinde frutos ontológicos y políticos si pensamos en el concepto de pluralidad 
de Arendt. Si ésta es el "hecho que los hombres, no el Hombre, vivan en la Tierra y habiten en el mundo" (Arendt, 2019: 22), entonces debemos pugnar por literaturas no dogmáticas, sino abiertas a los sujetos pues estos no tienen un solo rostro sino varios que el arte puede representar de buena manera. En las textualidades abiertas, la palabra puede recoger a aquellos que no están siendo atendidos.

Ello se producirá, entre otras cosas, porque el esfuerzo emancipatorio del lector y de los sujetos de la obra lo exigen así. Atrás quedan las identidades fijas y en su lugar se alumbran cruces insospechados por donde pasa el sujeto. Ese viaje identitario que rebasa las categorías jurídicas del siglo XIX, es difuso, impuro, pues la experiencia posmoderna se desarrolla de esa manera y los sujetos perciben y se autoperciben como desarraigados, pero atados a alguna forma de territorio. La migración, o sea, ese estar desplazado de sí mismo, es un concepto que no sólo alumbra al sujeto contemporáneo sino que ilumina los estudios de Derecho y Literatura en su totalidad, pues éstos se forman en la tensión de dos ramas. De ahí que el diálogo sea fundamental para poder observar los frutos que necesitamos.

En ese sentido, creo que la figura del imbunche puede prestarse para relaciones filosóficas, corporales, políticas, históricas, jurídicas, que en nuestro continente están vigentes y actuando. No de otra manera puedo pensar en las palabras de Valdés cuando señala que el imbunche "es toda una forma de adaptarse a la existencia; es todo un mundo que hace necesaria esa forma de adaptación". Se trata de un lenguaje propio que implica una "forma de conocimiento de la realidad que no puede entregarse sino en y por su propio lenguaje" (Valdés, 1975: 131-132).

Es la confianza que señala Steiner entre los sujetos y la palabra. Para nosotros será la confianza entre el espacio (poética), la palabra (literatura), el sujeto (migrante) y el mundo, que corresponde a un acto que es el acto fundamental de nuestro ser, mucho más que "cualquier 'contrato social o alianza con el postulado de lo divino" (Steiner, 1991: 114).

Si lo anterior es cierto y, por otro lado, las narraciones míticas fundan un mundo, entonces puede ser que, como reza la historia, esas cuevas donde se esconde el imbunche no estén localizadas en un punto específico del mapa chileno, sino que se extiendan por todo el país y, quizás (deteniéndose en las particularidades de cada espacio), por todo el continente. 


\section{Bibliografía:}

Arendt, H. (2020): La vida del espíritu. Barcelona, Paidós.

Arendt, H. (2019): La condición humana. Barcelona, Paidós.

Bajtín, M. (2017): Problemas de la poética de Dostoievski. Ciudad de México, Fondo de Cultura Económica.

Ballart, P. (2005): El contorno del poema. Barcelona, Editorial Acantilado.

Barthes, R. (1977): “Literatura y significación”, en R. Barthes, Ensayos críticos. Barcelona, Seix Barral, pp. 309-330.

Bisama, Á. (2021): "Prólogo. El terror”, en Donoso. J. El obsceno pájaro de la noche. Barcelona, Alfaguara, pp. 9-14.

Cabanne, P. (2013): Conversaciones con Marcel Duchamp. Barcelona, Centro de Artes Visuales Fundación Helga de Alvear.

Calvo, J. (2012): "Derecho y Literatura. Intersecciones instrumental, estructural e institucional", en J. Calvo, El escudo de Perseo. La cultura literaria del derecho. Granada, Editorial Comares, pp. 297-321.

Catrileo, D. (2017): El territorio del viaje. Archipiélago ediciones.

Cornejo Polar, A. (2003): Escribir en el aire. Ensayo sobre la heterogeneidad sociocultural en las literaturas andinas. Lima, CELACP, Latinoamericana editores.

Cornejo Polar, A. (1980): "Sobre el concepto de heterogeneidad: Respuesta a Roberto Paoli”, Revista de Crítica Latinoamericana, 6(12), pp. 87-91.

Donoso, J. (2021): El obsceno pájaro de la noche. Barcelona, Alfaguara.

Droguett, C. (1971): El obsceno éxito de José Donoso. Disponible en web: http://letras.mysite.com/jdon120219.html [Consulta: 13 de octubre de 2021]

Eagleton, T. (2017): Cómo leer literatura. Barcelona, Ediciones península.

Falconí, D. (2012): Las entrañas del sujeto jurídico. Un diálogo entre la literatura y el derecho. Barcelona, Editorial UOC. 
Falconí, D. (2016): “Presentación del dossier: Derecho y Literatura en América Latina”, Revista de Derecho Iuris Dictio, 18, pp. 13-18.

Galster, I. (1994): “Algunas preguntas a Antonio Cornejo Polar sobre teoría y crítica literarias latinoamericanas", Iberoamericana (1977-2000), 3/4 (55/56), 18, pp. 103108.

González, R. (2000): Mito y archivo. Una teoría de la narrativa latinoamericana. México D.F., Fondo de Cultura Económica.

Hozven, R. (2012): "Imbunche y majamama, dos archivos culturales chilenos", Atenea, 506, pp. 153-169.

Karam, H. (2019): "O papel do autor nos estudos do direito na ou através da literatura", Revista Electrónica do Curso de Direito da UFSM, 14(3), pp. 1-25.

Luque, P. (2020): Las cosas como son y otras fantasías. Moral, imaginación y arte narrativo. Barcelona, Anagrama.

Marí, E. (1998): "Derecho y literatura. Algo de lo que sí se puede hablar pero en voz baja”, Doxa. Cuadernos de Filosofía del Derecho, 21(2), pp. 251-287.

Mayer, H. (1977): Historia maldita de la literatura. La mujer, el homosexual, el judío. Madrid, Taurus.

Moraña, M. (1999): "Antonio Cornejo Polar y los debates actuales del latinoamericanismo: noción de sujeto, hibridez, representación", Revista de Crítica Literaria Latinoamericana, 50, pp. 19-28.

Pereira, Á. (2017): Trasandina de Ivonne Coñuecar: [el desarraigo de los hielos]. Disponible en web: http://letras.mysite.com/icon100517.html. [Consulta: 13 de octubre de 2021]

Plath, O. (2016): Geografía del mito y la leyenda chilenos. Santiago de Chile. Fondo de Cultura Económica.

Pron, P. (2011): "Exploradores del abismo", en P. Pron, El mundo sin las personas que lo afean y lo arruinan. Buenos Aires. Randon House Mondadori, pp. 201- 209.

Roggero, J. (2012): "Derecho c/literatura”, Revista Filosofía del Derecho, 1, pp. 173193. 
Sánchez, C. (2003): Hannah Arendt. El espacio de la política. Madrid, Centro de Estudios Políticos y Constitucionales.

Sepúlveda, F. (2010): Patrimonio, identidad, tradición y creatividad. Santiago de Chile, Centro de investigaciones Barros Arana.

Sosa, C. (2020): La hija de Sandro. Buenos Aires, Tusquets.

Steiner, G. (1991): Presencias reales. Barcelona, Ediciones destino.

Uribe, C. (2009): "El culto a lo feo y el invunchismo en Chile según Joaquín Edwards Bello", Revista Chilena de Literatura, 75, pp. 233-258.

Valdés, A. (1975): "El "imbunche". Estudio de un motivo en El obsceno pájaro de la noche", en A. Cornejo Polar, coord., José Donoso: la destrucción de un mundo. Buenos Aires, García Cambeiro, pp. 126 - 160.

Valdivieso, J. (1990): "Significación del mito en la literatura latinoamericana", Revista de Estudios Públicos, 39, pp. 275- 281.

Fecha de recepción: 17 de julio de 2021

Fecha de aceptación: 13 de octubre de 2021 